\title{
De ervaringen van multiprobleemgezinnen met communicatie in de zorg
}

\author{
Irene Moor · Noortje Pannebakker · Sophie Wins · Paul Kocken
}

Published online: 5 November 2018

(C) Bohn Stafleu van Loghum is een imprint van Springer Media B.V., onderdeel van Springer Nature 2018

\begin{abstract}
Binnen de jeugdzorg worden gezinnen die meervoudige, complexe en persistente problemen in verschillende levensdomeinen ervaren, aangeduid als multiprobleemgezinnen. Naar schatting zijn er 3-5\% multiprobleemgezinnen in Nederland [1]. Multiprobleemgezinnen onderscheiden zich door de complexiteit van de problematiek. Kenmerkend voor multiprobleemgezinnen is dat zowel ouders als kinderen veel gebruikmaken van zorg $[2,3]$. Deze zorg valt veelal onder de Jeugdwet in het sociale domein.
\end{abstract}

\section{Communicatie als indicator voor de kwaliteit van zorg}

Gezinnen met meerdere problemen blijken vaker ontevreden over de geleverde zorg, wat kan leiden tot een vicieuze cirkel, waarbij het gezin vroegtijdig stopt, om later weer terug te keren in de zorg als problemen onopgelost blijven [4]. Om de zorg voor multiprobleemgezinnen efficiënter te laten verlopen wordt veel gebruikgemaakt van de methode 1Gezin1Plan. Uit een kwalitatief onderzoek blijkt dat deze werkwijze over het algemeen positief wordt ontvangen door multiprobleemgezinnen, hoewel de afstemming tussen gezin en zorgverleners nog niet altijd even soepel verloopt [5]. Juist omdat er verschillende zorgverleners tegelijkertijd betrokken zijn bij deze gezinnen, is goede communicatie belangrijk, opdat zowel met professionals onderling als met het gezin goed kan worden afgestemd welke zorg nodig is [5, 6]. De kwaliteit van de communicatie tussen ouders en zorgverleners is een belangrijke indicator voor de kwaliteit van de zorg. Deze communicatie kan

I. Moor · N. Pannebakker $\cdot$ S. Wins $\cdot$ P. Kocken $(\bowtie)$

Afdeling Child Health en Academische Werkplaats Jeugd

'SAMEN', TNO, Leiden, Nederland

paul.kocken@tno.nl worden ingedeeld in gezamenlijke besluitvorming, affectieve communicatie en informatieverstrekking. De andere belangrijke indicator is interprofessionele communicatie, ofwel de communicatie tussen zorgverleners [6]. Meer inzicht in de ervaringen van multiprobleemgezinnen met ouder-zorgverlenercommunicatie en interprofessionele communicatie draagt er mogelijk toe bij dat de zorg beter op deze doelgroep kan worden toegespitst en het zorggebruik afneemt.

Het doel van dit onderzoek was om na te gaan of multiprobleemgezinnen en gezinnen met milde tot ernstige problemen verschillen in ervaren communicatie met de zorgverlener en de ervaren interprofessionele communicatie. Tevens is onderzocht of ouder-hulpverlenercommunicatie en interprofessionele communicatie samenhangen met tevredenheid over de zorg.

\section{Methode}

Voor dit cross-sectionele onderzoek zijn baseline-data gebruikt van een cohort van 354 gezinnen uit Den Haag en Leiden [7]. De ouders hadden een kind tussen de achttien maanden en twaalf jaar oud. Gezinnen werden geïncludeerd indien het kind (een risico op) complexe problemen had en moesten daarvoor aan een of meer van de volgende criteria voldoen: (1) het kind heeft psychosociale problemen (volgens SDQ [8] en BITSEA [9]), (2) er is sprake van een persistent opvoedingsprobleem, (3) een of meer belangrijke levensgebeurtenissen hebben plaatsgevonden in het jaar voorafgaand aan het consult (4) het zorggebruik van de ouder en/of het kind. In dit onderzoek zijn de gegevens van 260 gezinnen geanalyseerd waarvan in ieder geval het kind zorg ontvangt.

De respondenten vulden een digitale vragenlijst in of werden telefonisch geïnterviewd in de taal van hun voorkeur. De vragenlijst bevatte vragen over zorgge- 
bruik, factoren die het gebruik van zorg bevorderen of belemmeren (bijvoorbeeld steun van familie), gezondheids- en opvoedproblemen van ouder en kind (bijvoorbeeld geestelijke gezondheidsproblemen van de ouder (GHQ12 [10])) en achtergrondkenmerken. Op basis van de antwoorden op de vragenlijst zijn de gezinnen vervolgens opgedeeld in twee groepen, namelijk multiprobleemgezinnen en gezinnen die milde tot ernstige problemen ervaren. Voor het maken van dit onderscheid werd het framework van Bodden en Dekovic gebruikt. Dit is gebaseerd op zeven domeinen, die betrekking hebben op (1) kindfactoren (bijvoorbeeld psychosociale problemen), (2) ouderfactoren (bijvoorbeeld de geestelijke gezondheid van de ouder), (3) opvoedingsfactoren (bijvoorbeeld zorgen over de opvoeding), (4) gezinsfactoren (bijvoorbeeld de relatie met het kind en/of de partner), (5) contextuele factoren (bijvoorbeeld levensgebeurtenissen), (6) sociale netwerkfactoren (bijvoorbeeld sociale steun) en (7) zorggebruik [2]. Een gezin werd als multiprobleemgezin gedefinieerd als het voldeed aan minimaal vijf van deze domeinen. Gezinnen die aan minder dan vijf criteria voldeden werden ingedeeld bij gezinnen met milde tot ernstige problemen [3].

Voor het meten van de concepten ouder-zorgverlenercommunicatie (gedeelde besluitvorming, affectieve communicatie, informatieverstrekking) en interprofessionele communicatie werden de CQ-Index en QUOTE-vragenlijsten gebruikt [11, 12]. Een voorbeeld van een vraag over ouder-zorgverlenercommunicatie is: 'De hulpverlener dringt mij/mijn kind geen advies of behandeling op.' Een voorbeeld van een vraag over interprofessionele communicatie is: 'Wat vindt $\mathrm{u}$ over het algemeen van de communicatie tussen de verschillende hulpverleners?' De tevredenheid over de zorg werd gemeten met een tienpuntsschaal.

\section{Resultaten}

Uit de analyses blijkt dat multiprobleemgezinnen hoger scoorden dan gezinnen met milde tot ernstige problemen op de ervaren communicatieaspecten gedeelde besluitvorming, affectieve communicatie en informatievoorziening (zie fig. 1). Wat betreft de door de ouders waargenomen interprofessionele communicatie was er geen significant verschil.

Tevens is onderzocht of ouder-zorgverlenercommunicatie en interprofessionele communicatie samenhingen met tevredenheid over de zorg. Alleen de interprofessionele communicatie bleek significant samen te hangen met een grotere tevredenheid over de zorg. Verdiepende analyses zijn verricht om te onderzoeken welke factoren verband houden met communicatie. Het bleek dat geestelijke gezondheidsproblemen van de ouder significant negatief samenhingen met interprofessionele communicatie.

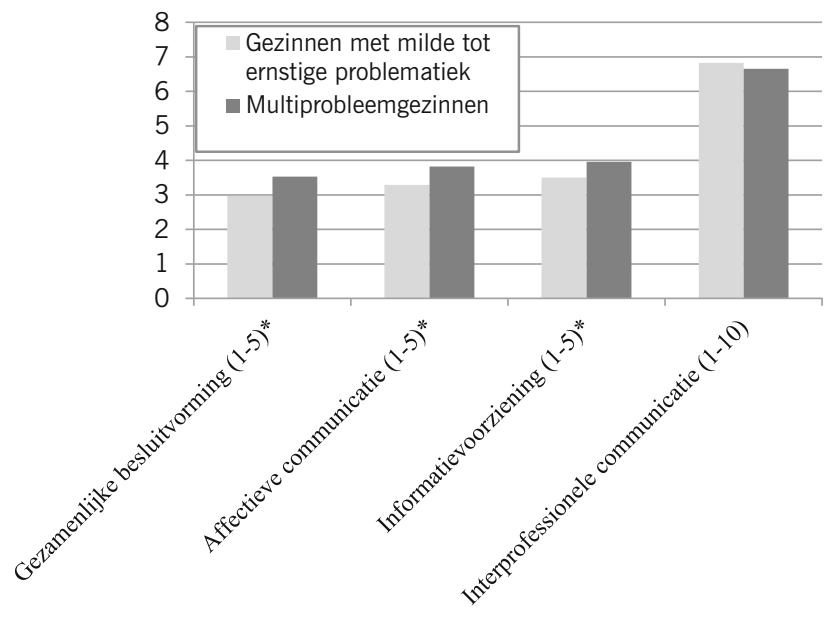

Figuur 1 Verschillen tussen multiprobleemgezinnen en andere gezinnen met milde tot ernstige problematiek als het gaat om tevredenheid met de verleende zorg $\left({ }^{*} p<0,01\right)$

\section{Beschouwing}

Dit onderzoek toont aan dat communicatie met de hulpverlener door gezinnen met een veelheid en complexiteit aan problemen relatief gunstig wordt beoordeeld, vergeleken met gezinnen die minder problemen hebben. Een mogelijke verklaring voor de hogere tevredenheidsscores met de ouder-zorgverlenercommunicatie is dat de gezinnen die hebben deelgenomen aan het onderzoek al langer in zorg waren. Hierdoor hadden de multiprobleemgezinnen de kans om een goede therapeutische relatie op te bouwen met de professionals. De samenhang tussen tevredenheid over de zorg en interprofessionele communicatie kan mogelijk worden verklaard door de nadruk die professionals leggen op goede afstemming, bijvoorbeeld door het in de regio's van dit onderzoek gebruikte $1 \mathrm{Ge}$ zin1Plan, als gebruik wordt gemaakt van verschillende typen zorg. Dergelijke methoden, die cliënt-hulpverlenercommunicatie en interprofessionele communicatie ondersteunen, zijn voor het sociale domein belangrijk. Dit onderzoek kent echter de beperking van een crosssectioneel onderzoeksontwerp, waardoor er geen causaal verband aangetoond kan worden. Bovendien betreffen de respondenten mogelijk een specifieke selectie doordat zij bereid en in staat waren mee te doen aan vragenlijstonderzoek. Misschien zijn gezinnen bij wie de zorg en de communicatie minder soepel verlopen minder goed bereikt.

\section{Conclusie}

Uit ons onderzoek blijkt dat aandacht voor communicatie met multiprobleemgezinnen en die tussen hulpverleners in de zorg belangrijk is. Daarnaast dienen hulpverleners bij hun onderlinge afstemming alert te zijn op de aanwezigheid van geestelijke gezondheidsproblemen van ouders van multiprobleemgezinnen. Dit onderzoek heeft enkele eerste inzichten opgele- 
verd met betrekking tot aspecten van communicatie bij hulp aan multiprobleemgezinnen. Longitudinaal en kwalitatief onderzoek is nodig om meer licht te werpen op de rol die communicatie speelt in de kwaliteit van zorg voor deze doelgroep.

\section{Literatuur}

1. Richtlijnen jeugdhulp en jeugdbescherming. Multiprobleemgezinnen. 2017. http://www.richtlijnenjeugdhulp. $\mathrm{nl} /$ multiprobleemgezinnen/. Geraadpleegd op 7 september 2018.

2. Bodden DH, Deković M. Multiproblem families referred to youth mental health: what's in a name? Fam Process. 2016;55:31-47.

3. Moor II. Parental evaluation of care in multi-problem families and the role of communication. Leiden: Rijksuniversiteit Leiden; 2016. Master thesis.

4. Tausendfreund T, Knot-Dickscheit J, Schulze GC, et al. Families in multi-problem situations: backgrounds, characteristics, and care services. Child Youth Serv. 2016;37:4-22.

5. Gilsing R, Hoff $M$ van der, Hal L van. 1Gezin1Plan in de praktijk. De meerwaarde van de werkwijze 1Gezin1Plan onderzocht. Utrecht: Verwey-Jonker Instituut; 2018.
6. Jager M. Unraveling the role of client-professional communication in adolescent psychosocial care. Groningen: Universiteit van Groningen; 2016. Doctoral dissertation.

7. Pannebakker NM, Kocken PL, Theunissen MH, et al. Services use by children and parents in multiproblem families. Child Youth Serv Rev. 2018;84:222-8.

8. Goodman R. The strengths and difficulties questionnaire: a research note. JChild Psychol Psychiatry. 1997;38:581-6.

9. Briggs-Gowan MJ, Carter AS, Irwin JR, et al. The brief infant-toddler social and emotional assessment: screening for social-emotional problems and delays in competence. J Pediatr Psychol. 2004;29:143-55.

10. Hankins M. The reliability of the twelve-item general health questionnaire (GHQ-12) under realistic assumptions. BMC Public Health. 2008;8:355.

11. Delnoij DMJ, Rademakers JJDJM, Groenewegen PP. The Dutch consumer quality index: an example of stakeholder involvement in indicator development. BMC Health Serv Res. 2010;10:88.

12. Nivel. Wat is QUOTE? 2018. http://www.nivel.nl/nl/watquote. Geraadpleegd op 7 september 2018. 